J. Lake Sci. (湖泊科学) , 2011, 23(1): 95-103

http: //www. jlakes. org. E-mail : jlakes@niglas.ac.cn

(c) 2011 by Journal of Lake Sciences

\title{
三峡水库水体漫衰减系数光学特性及其遥感反演”
}

\author{
徐神凡 ${ }^{1}$, 李云梅 ${ }^{1}$, 王 桥 $^{2}$, 吕 恒 $^{1}$, 刘忠华 ${ }^{1}$, 徐 昕 ${ }^{1}$, 檀 静 $^{1}$, 郭宇龙 ${ }^{1}$, 吴传庆 ${ }^{2}$ \\ ( 1 : 南京师范大学虚拟地理环境教育部重点实验室, 南京 210046) \\ (2: 环境保护部卫星环境应用中心, 北京 100029)
}

\begin{abstract}
摘 要: 根据 2009 年 8 月 $22-24$ 日实测的三峡水库水体的光谱数据以及水质参数,对三峡水库漫衰减系数的光学特性 及影响因子进行分析研究, 构建了 $490 \mathrm{~nm}$ 处漫衰减系数的 $K_{d}(490)$ 反演模型, 并利用环境一号卫星 CCD 数据对 2009 年 7 月 21 日的三峡水库 $K_{d}(490)$ 进行反演. 结果表明: 由于水体中非色素颗粒物的含量较高,使得研究区大部分点位的 $K_{d}$ 值 在 $440 \mathrm{~nm}$ 和 $675 \mathrm{~nm}$ 处的衰减峰值不明显, 对 $K_{d}$ 占主导地位的影响因子是颗粒物的吸收作用以及水体的总散射作用,在所 选的四个特征波段 $\left(440 、 550 、 613\right.$ 和 $675 \mathrm{~nm}$ ) 处,其贡献率的均值分别为 $45.48 \%$ 和 $38.21 \%$; 在 $400-700 \mathrm{~nm}$ 波段范围, $K_{d}$ 与非色素颗粒物浓度具有很好的幂函数关系. 利用地面实测遥感反射率模拟环境卫星第三波段构建 $K_{d}(490)$ 反演模型, 其平均相对误差为 $17.89 \%$, 直接利用卫星数据反演的相对误差为 $28.38 \%$; 研究区中 $K_{d}(490)$ 主要集中在 $6-7 \mathrm{~m}^{-1}$, 占 研究区域面积的 $83.60 \%$,相比而言, 人库支流的 $K_{d}(490)$ 较干流要低, 表明支流颗粒物含量相对较低.
\end{abstract}

关键词: 漫衰减系数; 三峡水库;环境一号卫星;遥感反射率

\section{Optical properties and retrieving of diffuse attenuation coefficient of the Three Gorges Reservoir by remote sensing}

\author{
XU Yifan ${ }^{1}$, LI Yunmei ${ }^{1}$, WANG Qiao ${ }^{2}$, LÜ Heng $^{1}$, LIU Zhonghua ${ }^{1}$, XU Xin ${ }^{1}$, TAN Jing ${ }^{1}$, GUO Yulong ${ }^{1} \&$ \\ WU Chuanqing ${ }^{2}$ \\ (1: Key Laboratory of Virtual Geographic Environment, Ministry of Education, Nanjing Normal University, Nanjing 210046, \\ P. R. China) \\ (2: Satellite Environment Application Center, Ministry of Environmental Protection, Beijing 100029,P. R. China)
}

\begin{abstract}
By using the in situ measured data of spectral reflectance and water quality parameters in Aug. 22 - 24, 2009, this study analyzed the spectral characteristics and affecting factors of diffuse attenuation coefficient $\left(K_{d}\right)$ of the Three Gorges Reservoir, and built a retrieving model of $K_{d}(490)$ at band $490 \mathrm{~nm}$. In addition, $K_{d}(490)$ was inversed by using CCD image of HJ-1 satellite in July 21,2009 . The results showed that the attenuation peaks were not distinct at bands $440 \mathrm{~nm}$ and $675 \mathrm{~nm}$ owing to the high content of non-pigment particulates in the water. The dominant affecting factors were absorption of particulates and total scattering of water body, while average contributions of the four bands(i. e. $440,550,613$ and $675 \mathrm{~nm}$ ) were $45.48 \%$ and $38.21 \%$, respectively; $K_{d}$ strongly power correlated with the concentration of non-pigment particles between 400 to $700 \mathrm{~nm}$. Besides, the average relative error of inversed vs. measured $K_{d}(490)$ was $17.89 \%$ for ground-measured $R_{r s}$, whereas the relative error for images data was $28.38 \% ; K_{d}(490)$ of the study area was concentrated from 6 to $7 \mathrm{~m}^{-1}$, which accounted for $83.60 \%$ of the study area. Additionally, $K_{d}(490)$ of the tributaries of the reservoir was lower than the main stream, which indicated that the content of particulates in tributaries was relatively low.
\end{abstract}

Keywords: Diffuse attenuation coefficient; Three Gorges Reservoir; HJ-1 satellite; remote sensing reflectance

* 国家科技重大专项项目 (2009ZX07527-006)、国家自然科学基金项目 (40971215)、江苏省普通高校研究生科研创 新计划项目 (CX09B - 301Z)、南京师范大学优秀博士论文培养计划项目 (12432116011036)、江苏省普通高校研究 生科研创新计划项目 (CX10B_392Z) 和南京师范大学优秀博士论文培育计划项目 (2010bs0036) 联合资助. $2010-$ 05-18 收稿;2010-09-06 收修改稿. 徐神凡, 男,1986 年生, 硕士研究生; E-mail : xuyifan1986@ 163. com. 
当水体中漫衰减系数较大时, 水下光场较弱, 水生植物可能会因为得不到足够的光照进行光合作用而 衰退或死亡, 从而导致水体生态系统类型发生转化, 因此漫衰减系数对水体生态环境具有重要影响 ${ }^{[1]}$. 此 外, 漫衰减系数的大小直接影响水体中光线的分布及变化, 可以反映水体的光学性质和光学类型, 是水体光 学研究中的一个重要参数. 漫衰减系数由水体中的颗粒物、黄质、纯水的吸收系数以及散射系数决定, 目前 对纯水的光学特性的研究已经比较充分 ${ }^{[1]}$, 且对于不同水体来说, 纯水的吸收作用对其影响是一致的. 所以 不同水体之间漫衰减系数的差异, 主要是由于水体中颗粒物、CDOM 等组分对光线的吸收和散射作用的效 果不同所致. 因而, 研究颗粒物、CDOM 等组分对光线的吸收和散射作用对漫衰减系数的影响就显得非常重 要. 目前, 国内对于内陆水体该方面的研究, 主要集中在太湖, 如张运林等、乐成峰等、黄昌春等对太湖漫衰 减系数特性的研究 ${ }^{[2-5]}$, 对其他内陆水体的研究还相对较少. 随着三峡水库蓄水, 长江中上游的河床河势和 水体的流动状态发生变化, 水质状况以及水体的光学性质和光学类型也随之发生改变, 这将对长江流域的 生态系统和环境产生重要影响. 对三峡水库水体漫衰减系数进行研究, 有助于了解三峡水库水体的光学特 性和光学类型及其对生态系统的影响, 更深人地分析水体生物、水文要素和水化学性质, 可为三峡水体的环 境质量评价和水体环境的生态修复提供基础资料.

由于遥感反射率 $R_{r s}$ 是离水辐亮度 $L_{w}$ 与水面人射辐照度 $E_{s}$ 的比值, 而 $90 \%$ 的 $L_{w}$ 来自于水层的上表面, 是由进人水体的光线经过水体组分的吸收、散射、衍射后, 散射光中向上的一部分以及浅水条件下水底反射 光共同组成的, 所以包含了大量的水体信息, 因此遥感反射率也间接地反映了水体各组分对光照的影响. 作 为可以在水面以上被光谱辐射仪以及遥感卫星等获取的包含水体特征的光谱信息, $R_{r s}$ 与同样被用来反映水 体表层光谱特性的 $K_{d}$ 具有良好的相关性 ${ }^{[6-7]}$. 卫星水色遥感一般均提供 $490 \mathrm{~nm}$ 波段漫衰减系数 $K_{d}(490)$ 作 为数据产品, 有关其反演模型算法的研究也受到了广泛的关注. 目前, 对于大洋一类水体的漫衰减系数的遥 感反演已有大量研究, 并有比较成熟的方法, 如 Austin 等提出了针对 CZCS 传感器, 基于 443 和 $550 \mathrm{~nm}$ 两个 波段离水辐亮度比值的线性关系反演漫衰减系数的算法 ${ }^{[8]}$; Mueller 通过研究 490 和 $555 \mathrm{~nm}$ 两个波段归一化 离水辐亮度比值的线性关系, 针对 SeaWiFS 传感器提出了反演漫衰减系数的算法 ${ }^{[9]}$; 崔廷伟等利用 2005 年 渤海近岸水体生物光学数据集, 建立了基于水体遥感反射率光谱 $R_{r s}(\lambda)$ 数据的 $490 \mathrm{~nm}$ 波段水体漫衰减系数 $K_{d}(490)$ 的经验反演模型, 并且以 ENVISAT MERIS 数据为例, 进行了模型的示范应用, 给出了渤海的 $K_{d}(490)$ 空间分布 ${ }^{[10]}$. 但是, 由于目前星载高光谱传感器的空间分辨率普遍较低, 使得其数据无法对内陆湖 泊、水库等较小面积的水体进行有效的反演, 而星载多光谱影像数据的空间分辨率则可以满足对内陆水体 光学参数的反演要求, 例如我国于 2008 年 9 月 6 日发射的环境一号卫星, 其上搭载的多光谱 CCD 传感器具 有 4 个波段 $(430-520 \mathrm{~nm}, 520-600 \mathrm{~nm}, 630-690 \mathrm{~nm}, 760-900 \mathrm{~nm})$, 空间分辨率为 $30 \mathrm{~m}$, 与目前的高光谱传感 器相比其较高的空间分辨率使其能够更加准确地体现参数的空间变化规律, 同时, 其 2 天的时间分辨率大 大增强了数据获取的可能性, 也使得对内陆湖泊水库进行长时间序列的监测成为可能. 对环境一号卫星 CCD 数据的评价表明:环境一号卫星 CCD 各波段在默认增益状态下的能量偏低,但各波段间的均衡性较 好; 在图像灰度分布层次方面, DN 范围较为集中, 各波段的灰度范围较窄; 纹理方面, 角二阶矩偏大, 图像纹 理较粗,但图像较平滑, 同时各波段的纹理差别较大, 一般按波段顺序呈递减趋势; 细节信号与信息容量方 面, 各波段的对比度总体上较好, 但熵值较低; 图像清晰程度方面, 图像的清晰度和功率谱较好; 边缘信号方 面, 表现良好. 总之, 环境一号卫星 CCD 数据的能量偏低, 但各波段能量表现均衡, 辐射质量 (熵值、纹理、细 节能量等) 各项指标均表现良好 ${ }^{[11]}$, 所以其影像数据可以在对地观测研究中正常应用.

本文对三峡库区水体漫衰减系数特性及基于环境一号卫星数据的反演方法进行研究. 首先, 在 2009 年 8月 22-24 日对三峡水库水体光谱信息进行实地测量、采样点水质分析的基础上,计算水库水体的漫衰减 系数, 并研究其光谱特性; 其次, 对其影响因子的贡献率进行分析比较; 最后, 基于环境一号卫星 CCD 数据的 波段设置建立 $K_{d}(490)$ 反演模型, 利用 2009 年 7 月 21 日三峡水库的 CCD 影像数据反演 $K_{d}(490)$, 并分析其 空间变化规律.

\section{1 材料与方法}

\section{1 研究区概况}

三峡大坝是世界上目前最大的水利枢纽工程, 是我国治理和开发长江的关键性骨干工程. 三峡水库位 
于湖北省三斗坪, 在葛洲坝水利枢纽上游约 $40 \mathrm{~km}$ 处, 三峡坝址以上控制面积约 $100 \times 10^{4} \mathrm{~km}^{2}$, 区间面积 $55907 \mathrm{~km}^{2}$, 河道长 $658 \mathrm{~km}^{[12]}$. 水库建成后正常蓄水位 $175 \mathrm{~m}$, 汗期防洪限制水位 $145 \mathrm{~m}$, 枯水季消落最低水位 $155 \mathrm{~m}$. 水库总库容和防洪库容分别为 $393 \times 10^{8} \mathrm{~m}^{3}$ 和 $221.5 \times 10^{8} \mathrm{~m}^{3}$. 人库多年平均径流量 $2692 \times 10^{8} \mathrm{~m}^{3}$, 出库 多年平均径流量 $4292 \times 10^{8} \mathrm{~m}^{3}, 79 \%$ 的径流量集中在汛期 6-10 月 ${ }^{[13]}$. 三峡水库具有防洪、发电、航运等巨大 的综合效益, 但是水库蓄水后, 库区水体的光学性质和光学类型必然发生改变, 并将对水质产生影响, 但这 一过程如何发生需要进行长时间的观测和评价.

\section{2 地面试验}

2009 年 8 月 $22-24$ 日对三峡水库 25 个采样点 (图 1 ) 进行了实地观测和水样采集. 测量参数包括: 野 外测量的水面以上遥感反射率、水面以下下行辐照度、 总散射系数和后向散射系数; 室内分析的悬浮颗粒、黄 质吸收系数以及悬浮颗粒物浓度.

水面光谱测量使用美国分析光谱仪器公司 (Analytical Spectral Devices) 生产的 ASD 野外光谱辐射仪 (ASD Field Spec), 测量方法采用的是 Mobley 和唐军武 等提出的水面以上测量法 ${ }^{[14-15]}$.

利用下式将水面实测光谱转换为遥感反射率 $R_{r s}$ :

$$
R_{r s}(\theta, \varphi, \lambda)=L_{w}(\theta, \varphi, \lambda) / E_{d}^{+}(\lambda)
$$

其中, $\theta$ 为观测天顶角, $\varphi$ 为观测方位角, $\lambda$ 为波长; $L_{w}(\theta, \varphi, \lambda)$ 为方向 $(\theta, \varphi)$ 上的离水辐射率 $\left(\mathrm{W} /\left(\mathrm{m}^{2}\right.\right.$.

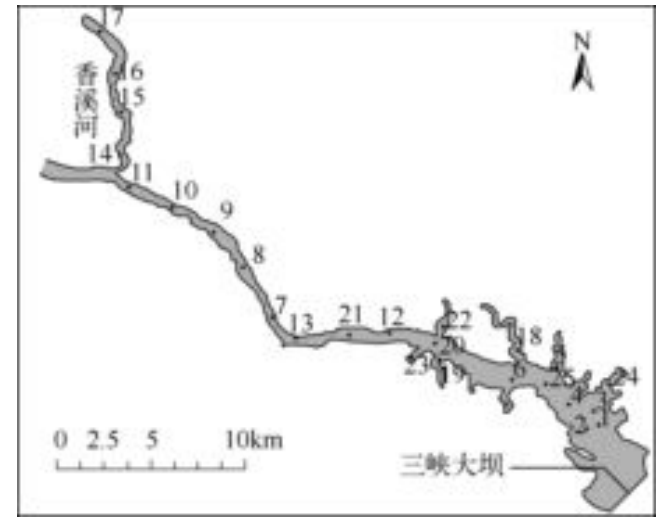

图 1 三峡水库数据采集样点分布

Fig. 1 Distribution of sampling stations in Three Gorges Reservoir $\mathrm{sr} \cdot \mathrm{nm})) ; E_{d}^{+}(\lambda)$ 为水体表面人射总辐照度.

水面以下的下行辐照度采用 TriOS 水下光谱仪进行测量, 测量波段范围为 $320-950 \mathrm{~nm}$, 光谱分辨率为 $3.3 \mathrm{~nm}$, 辐照度探头的测量饱和值为 $10 \mathrm{~W} /\left(\mathrm{m}^{2} \cdot \mathrm{nm}\right)(400 \mathrm{~nm}) 、 8 \mathrm{~W} /\left(\mathrm{m}^{2} \cdot \mathrm{nm}\right)(500 \mathrm{~nm}) 、 14 \mathrm{~W} /\left(\mathrm{m}^{2} \cdot \mathrm{nm}\right)$ $(700 \mathrm{~nm})$; 测量方法采用剖面测量法, 测量深度为 $20 、 40 、 60 、 80$ 和 $100 \mathrm{~cm}^{[16]}$.

水体颗粒物散射系数通过 Wetlabs 公司的光谱吸收和衰减仪 (AC-S ) 获得 ${ }^{[17]}, \mathrm{AC}-\mathrm{S}$ 在可见光波段范围 共有 85 个光谱通道, 光谱分辨率为 $4 \mathrm{~nm}$, 测量精度为 $0.01 \mathrm{~m}^{-1}$. AC-S 直接测量获得的是水体吸收系数 $a(\lambda)$ 和衰减系数 $c(\lambda)$, 并通过两者相减得到水中颗粒物的散射系数 $b_{p}(\lambda)$, 为了得到更为精确的吸收系数数据, 需对吸收系数进行温度、散射纠正 ${ }^{[14]}$,具体校正方法参见文献 $[18]$.

水体中颗粒物后向散射系数通过 Wetlabs 公司的散射仪 (BB9) 获得, BB9 共有 9 个光谱通道, 分别是 $400 、 440 、 488 、 510 、 532 、 595 、 660 、 676$ 和 $715 \mathrm{~nm}$, 测量精度为 $0.005 \mathrm{~m}^{-1}$. 由于 BB9 使用的是微球散射体, 由散 射引起的衰减部分, 使用 Scale factor (由 Wetlabs 公司提供) 纠正成为水体总体散射函数, 总体散射函数利用 (2) 式进行吸收纠正.

$$
\beta(\lambda)^{*}=\beta(\lambda) \exp (0.031 a)
$$

式中, $\beta(\lambda){ }^{*}$ 是吸收纠正后的总体散射函数; $\beta(\lambda)$ 是吸收纠正前的总体散射函数; $a$ 是相应波段的纠正后的 吸收系数. 由纠正后得到的总体散射函数, 减去纯水的体散射函数, 获得颗粒物的体散射函数 $\beta_{b}(\lambda)$.

根据公式(3)得到颗粒物后向散射系数 $b_{b p}(\lambda)^{[19]}$.

$$
b_{b p(\lambda)}=2 \pi X \beta_{b}(\lambda)(X=1.1 \text {, 误差为 } 4 \%)
$$

悬浮颗粒的浓度采用重量法测定: 将所有水样用煅烧过的 GF/C (Whatman) 过滤膜过滤, 将滤膜在 $110^{\circ} \mathrm{C}$ 条件下烘干 $4 \mathrm{~h}$ 称量, 再除以过滤的水样体积.

吸收系数的测量均在岛津 UV22550 分光光度计中进行: 采用定量滤膜法测得颗粒物的吸收系数. CDOM 吸收系数采用 $5 \mathrm{~cm}$ 光程比色且测量 ${ }^{[20]}$. 


\section{3 研究方法}

1.3.1 漫衰减系数计算方法及理论基础 光照在水质均一的水体中传播遵循指数衰减规律 ${ }^{[21]}$, 如式 (4):

$$
K_{d}(\lambda)=-\frac{1}{z} \ln \left[\frac{E_{d}(\lambda, z)}{E_{d}(\lambda, c)}\right]
$$

式中, $K_{d}(\lambda)$ 为波长为 $\lambda$ 处的水体漫衰减系数, $z$ 为从参考水层到测量处的深度, $E_{d}(\lambda, z)$ 为 $z$ 深度处的向下 辐照度 $\left(\mathrm{W} /\left(\mathrm{m}^{2} \cdot \mathrm{sr} \cdot \mathrm{nm}\right)\right), E_{d}(\lambda, c)$ 为参考水层深度处的辐照度 $\left(\mathrm{W} /\left(\mathrm{m}^{2} \cdot \mathrm{sr} \cdot \mathrm{nm}\right)\right)$.

通过对不同深度 $(20 、 40 、 60 、 80$ 和 $100 \mathrm{~cm})$ 的下行辐照度进行指数回归获得 $K_{d}$, 当 $R^{2} \geqslant 0.95$, 深度数 $\geqslant 3$ 时, $K_{d}$ 为有效值 ${ }^{[22]}$.

根据相关研究 ${ }^{[5]}$, 平均漫衰减系数 $K_{d}(a v)$ 可以表示为:

$$
K_{d}(a v) \approx \frac{a}{\bar{u}_{0}}\left[1+\frac{b}{a}\left(1-\bar{u}_{s}\right)\right]
$$

其中, $\bar{u}_{0}$ 为水表面以下太阳天顶角余弦值, $a$ 为吸收系数, $b$ 为散射系数, $\bar{u}_{s}$ 为散射相函数的平均余弦值. 式 (5) 中吸收系数 $a$ 可进一步分解为纯水的吸收系数 $a_{w}$ 、 CDOM 的吸收系数 $a_{y}$ 以及颗粒物的吸收系数 $a_{p}$, 所 以式(5) 可以表示为:

$$
K_{d}(a v) \bar{u}_{0}=\left[a_{w}+a_{y}+a_{p}+b\left(1-\bar{u}_{s}\right)\right]
$$

对实测的后向散射系数 $b_{b}$ 和散射系数 $b$ 进行参数化, 继而得到研究水域水体平均后向散射概率为 0.006015 , 对应的 $\bar{u}_{s}$ 为 0.9718 ; 最大后向散射概率为 0.0195 , 对应的 $\bar{u}_{s}$ 为 0.9136 ; 最小后向散射概率为 0.0017 , 对应的 $\bar{u}_{s}$ 为 0.992 . 这里采用平均后向散射概率作为系数代人式 $(6)$ :

$$
K_{d}(a v) \bar{u}_{0}=\left[a_{w}+a_{y}+a_{p}+0.0282 b\right]
$$

根据式 (7), 采用颗粒物、CDOM、纯水的吸收系数以及总散射系数与漫衰减系数的比值作为这些组分对 漫衰减系数的贡献率, 并选用 $440 \mathrm{~nm}, 550 \mathrm{~nm}, 613 \mathrm{~nm}$ 和 $675 \mathrm{~nm}$ 为特征波段对贡献率大小进行对比分析 (440nm 和 $675 \mathrm{~nm}$ 为以往研究中内陆水体中一个明显的漫衰减系数的衰减峰值 ${ }^{[2]}$; 在 $550 \mathrm{~nm}$ 处, 虽然色素颗 粒物以及 CDOM 的吸收作用较小, 但非色素颗粒物的吸收和散射作用很大; $613 \mathrm{~nm}$ 处为漫衰减系数的曲线 由指数衰减到不规则变化的一个拐点).

1.3.2 影像数据预处理 由于没有与野外实测数据同步的卫星影像, 所以本研究中使用的是 2009 年 7 月 21 日三峡水库的环境一号卫星 CCD 数据, 这一时期水库的水位、人库流量等条件基本与野外实测时期的相 同 ${ }^{[23]}$. 对原始影像数据进行辐射定标、几何校正、大气校正等预处理.

(1) 辐射定标:采用式 (8) 将 CCD 传感器获取的 $D N$ 值转化为辐亮度数据:

$$
L=D N / a+L_{0}
$$

式中, $L$ 为辐亮度, $a$ 为绝对定标系数增益, $L_{0}$ 为偏移量, 转换后辐亮度单位为 $\mathrm{W} /\left(\mathrm{m}^{2} \cdot \mathrm{sr} \cdot \mathrm{nm}\right)$. 其中 $a$ 和 $L_{0}$ 的具体参数由 《环境减灾星座 $\mathrm{A} / \mathrm{B}$ 星各载荷在轨绝对辐射定标系数》 ${ }^{[24]}$ 提供.

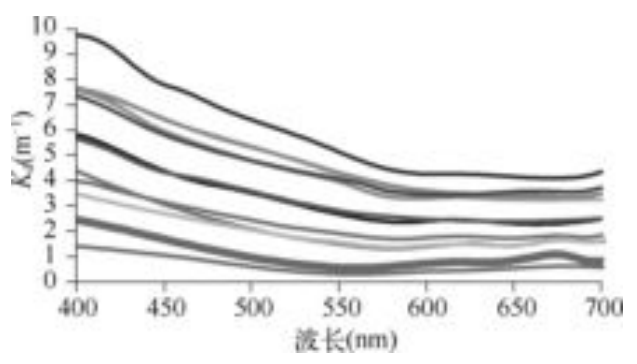

图 2 利用太阳天顶角归一化的 $K_{d}$

Fig. $2 K_{d}$ normalized by solar zenith angle

（2）几何校正与大气校正: 几何校正采用经过几何 精校正的同时期 TM 影像进行,校正精度保证在 0.3 个像 元以内. 大气校正采用 $6 \mathrm{~S}$ 模型 (Second Simulation of the Satellite Signal in the Solar Spectrum) 进行.

\section{2 结果与分析}

\section{1 三峡水库水体漫衰减系数特性}

对 $K_{d}$ 进行太阳天顶角归一化处理 (图 2), 以消除表 观光学量对 $K_{d}$ 的影响, 即 $K_{d} / \bar{u}_{0}$, 这里 $\bar{u}_{0}$ 为水表面以下太 阳天顶角余弦值. 可以看出, 三峡水库水体漫衰减系数变 
化特征较为明显: $400-613 \mathrm{~nm}$,大部分点位的漫衰减系数呈指数衰减; $613-700 \mathrm{~nm}$, 漫衰减系数相对来说变 化不大,但由于不同点位水体中各组分所占比例不同,所以点位之间的漫衰减系数出现不同的变化,部分点 位由于颗粒物中的色素颗粒物含量略高,使得受色素颗粒物中叶绿素 a 吸收系数影响的 $675 \mathrm{~nm}$ 处出现衰减 的峰值. 由于三峡水库的非色素颗粒物普遍含量很高, 使得色素颗粒物的吸收系数在大部分点位都被非色 素颗粒物以及 CDOM 的吸收系数所掩盖, 尤为明显的是在 $440 \mathrm{~nm}$ 处,色素颗粒物中的叶绿素 a 在这个波段 有明显的吸收峰, 会导致漫衰减系数出现衰减峰值 ${ }^{[25]}$, 但三峡水库的漫衰减系数光谱曲线并没有这一特征.

三峡水库的水体漫衰减系数不同点位之间变化很大, 在其波长 $440 \mathrm{~nm}$ 处, 漫衰减系数最大值为 $8.28 \mathrm{~m}^{-1}$, 最小值为 $1.11 \mathrm{~m}^{-1}$, 平均值为 $(4.23 \pm 2.20) \mathrm{m}^{-1}$; 在波长 $550 \mathrm{~nm}$ 处, 漫衰减系数最大值为 $5.16 \mathrm{~m}^{-1}$, 最小值为 $0.37 \mathrm{~m}^{-1}$, 平均值为 $(2.49 \pm 1.58) \mathrm{m}^{-1}$; 在波长 $675 \mathrm{~nm}$ 处, 漫衰减系数最大值为 $4.16 \mathrm{~m}^{-1}$, 最小值为 $0.65 \mathrm{~m}^{-1}$, 平均值为 $(2.26 \pm 1.08) \mathrm{m}^{-1}$. 由此可见, 三峡水库不同区域水体组分对光线在水下传播影响以及 水下光场的分布是不同的.

\section{2 三峡水库漫衰减系数影响因子}

漫衰减系数受散射及吸收特性影响,其中吸收特性又受到颗粒物、CDOM、纯水吸收的共同作用,且不同 参数在不同波段对衰减贡献的大小不同. 颗粒物和 CDOM 的吸收系数曲线类似 (图 $3 \mathrm{a} 、 \mathrm{~b})$, 都是随着波长增 加呈指数衰减的趋势, CDOM 在紫外波段以及可见光的蓝光波段表现出有很强的吸收特性,但随着波长的增 加,吸收系数迅速下降,而颗粒物的吸收特性主要集中在可见光波段. 在 $440 \mathrm{~nm}$ 波段处, CDOM 的吸收系数最 大值为 $1.08 \mathrm{~m}^{-1}$, 最小值为 $0.29 \mathrm{~m}^{-1}$, 平均值为 $(0.53 \pm 0.15) \mathrm{m}^{-1}$, 颗粒物的吸收系数最大值为 $13.42 \mathrm{~m}^{-1}$, 最小 值为 $0.73 \mathrm{~m}^{-1}$, 平均值为 $(4.98 \pm 3.61) \mathrm{m}^{-1}$; 在 $550 \mathrm{~nm}$ 波段处, CDOM 的吸收系数最大值为 $0.38 \mathrm{~m}^{-1}$, 最小值为 $0.01 \mathrm{~m}^{-1}$, 平均值为 $(0.14 \pm 0.10) \mathrm{m}^{-1}$, 而颗粒物的吸收系数的平均值为 $(1.71 \pm 1.48) \mathrm{m}^{-1}$. 以不同水体组分的 吸收系数以及总散射系数与漫衰减系数的比值为参数 (纯水的吸收系数参照 Robin 等测量的值 ${ }^{[26]}$ ), 评价不 同组分对漫衰减系数的贡献率 (表 1 ).

表 1 影响因子对 $K_{d}$ 贡献率的统计分析

Tab. 1 Statistic analysis of contribution of each influence factor

\begin{tabular}{|c|c|c|c|c|c|}
\hline 波长 $(\mathrm{nm})$ & 组分 & 最大贡献率( \% ) & 最小贡献率( \% ) & 均值 (\%) & 标准差(％) \\
\hline \multirow[t]{4}{*}{440} & 总散射作用 & 29.32 & 8.03 & 19.55 & 8.82 \\
\hline & 颗粒物 & 89.75 & 48.32 & 70.18 & 15.10 \\
\hline & CDOM & 26.75 & 2.17 & 10.15 & 7.68 \\
\hline & 纯水 & 0.21 & 0.0414 & 0.12 & 0.01 \\
\hline \multirow[t]{4}{*}{550} & 总散射作用 & 51.01 & 18.84 & 36.63 & 13.90 \\
\hline & 颗粒物 & 78.84 & 33.65 & 56.08 & 17.86 \\
\hline & CDOM & 19.23 & 0.50 & 4.92 & 6.06 \\
\hline & 纯水 & 3.87 & 0.91 & 2.37 & 1.10 \\
\hline \multirow[t]{4}{*}{613} & 总散射作用 & 62.19 & 33.79 & 47.65 & 12.18 \\
\hline & 颗粒物 & 55.64 & 17.73 & 33.63 & 16.87 \\
\hline & CDOM & 15.32 & 0 & 3.48 & 5.08 \\
\hline & 纯水 & 21.13 & 8.24 & 15.24 & 5.01 \\
\hline \multirow[t]{4}{*}{675} & 总散射作用 & 65.05 & 38.95 & 49.02 & 9.62 \\
\hline & 颗粒物 & 39.80 & 9.93 & 22.01 & 12.16 \\
\hline & CDOM & 5.75 & 0 & 1.38 & 2.00 \\
\hline & 纯水 & 34.94 & 17.88 & 27.59 & 6.92 \\
\hline
\end{tabular}

在 $440 \mathrm{~nm}$ 和 $550 \mathrm{~nm}$ 处, 水体中的颗粒物的吸收作用对 $K_{d}$ 的贡献率最大, 均值分别达到了 $70.18 \%$ 和 $56.08 \%$.三峡水库水体颗粒物的吸收系数特征曲线与非色素颗粒物相似 (图 $3 \mathrm{~b}, \mathrm{c}$ ), 原因是在本次研究期间 三峡水库大部分水域中非色素颗粒物在总悬浮颗粒物中占有绝对优势,在对采集的水样进行检测后发现， 非色素颗粒物的浓度远高于色素颗粒物浓度, 二者的均值分别为 $56 \mathrm{mg} / \mathrm{L}$ 和 $9 \mathrm{mg} / \mathrm{L}$, 这就造成非色素颗粒物 吸收在 $440 \mathrm{~nm}$ 和 $550 \mathrm{~nm}$ 波段的贡献要远远大于色素颗粒物, 致使色素颗粒物的吸收特征淹没在其中. 而颗 
粒物对于 $K_{d}$ 贡献率的标准差在四个特征波段都相对较大,最大达到 $17.86 \%$, 这说明三峡水库不同区域水体 中的颗粒物含量以及颗粒物的组成成分存在较大差别. 而随着波长的增加, 颗粒物的吸收系数下降, 进而使 得其在 $K_{d}$ 中的贡献率下降, 在 $613 \mathrm{~nm}$ 以及 $675 \mathrm{~nm}$ 波段处, 水体中的总散射作用对 $K_{d}$ 的贡献率超过颗粒物的 吸收作用, 水体的散射作用的光谱曲线特征较为单一, 各点位的散射系数光谱均是近似的倾斜直线, 并且随 波长增大而减小, 但各点位散射系数之间变化较大, 这同样说明三峡水库不同区域之间水体组分的差异较 大(图 3). 如前文所述, CDOM 的吸收作用主要集中在紫外波段以及可见光的蓝光波段, 对蓝光之外的波长 较长的可见光波段吸收很少, 所以在选取的四个特征波段中, CDOM 对 $K_{d}$ 的贡献率由 $440 \mathrm{~nm}$ 的均值 $10.15 \%$ 降低到 $675 \mathrm{~nm}$ 的 $1.38 \%$.
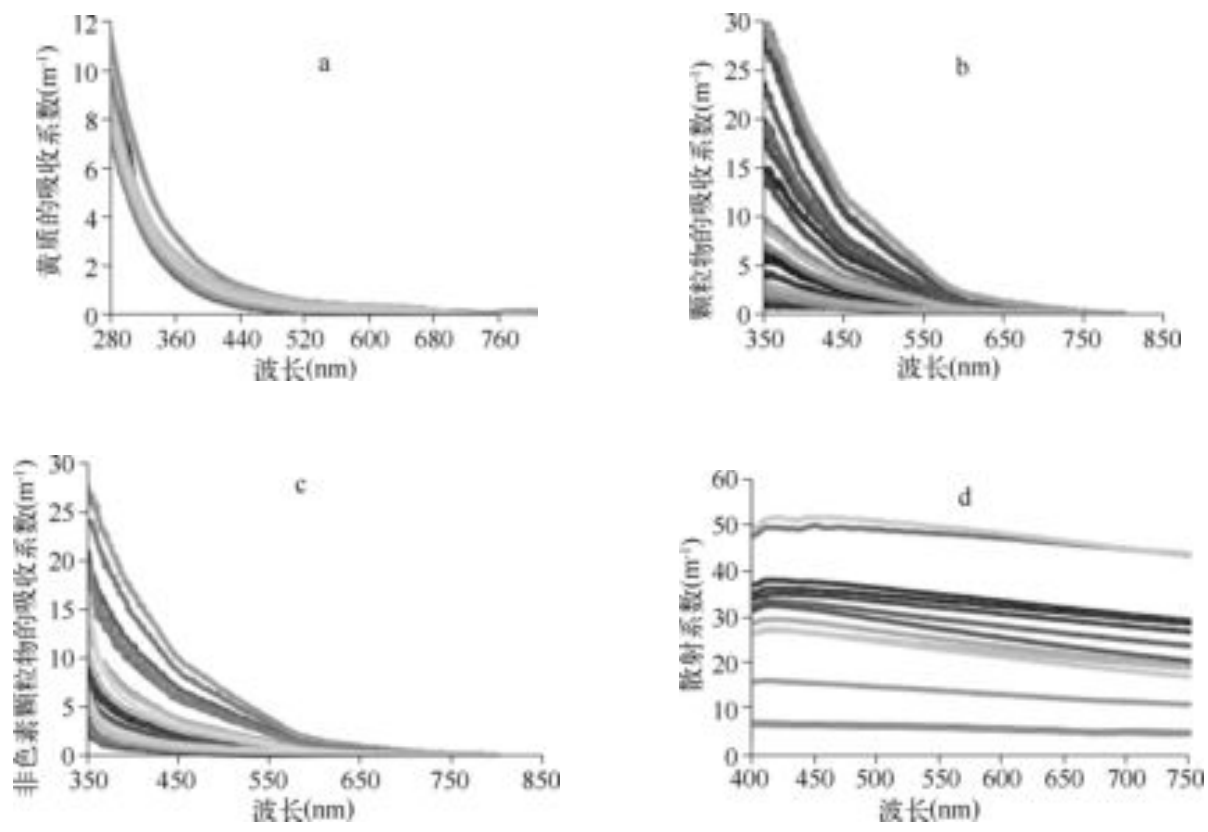

图 3 黄质 $(\mathrm{a})$ 、颗粒物 $(\mathrm{b})$ 、非色素颗粒物 (c) 的吸收曲线及散射系数曲线 $(\mathrm{d})$

Fig. 3 Absorption curves of $\operatorname{CDOM}(a)$, particulate(b), non-pigment particulate(c), and scattering coefficient(d)

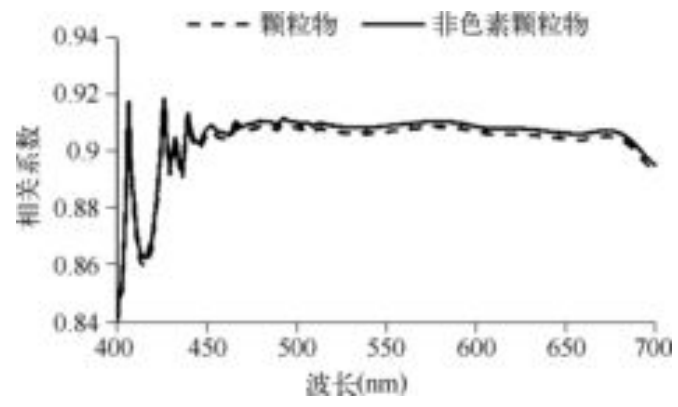

图 4 漫衰减系数与颗粒物和非色素颗粒 物浓度的相关性

Fig. 4 Correlation between diffuse attenuation coefficient with particulate and non-pigment particulate

\section{3 三峡水库漫衰减系数的遥感影像反演}

2.3 .1 漫衰减系数与遥感反射率的关系 采用地面实测的高光谱数据模拟星上数据, 根据环境一号卫星的
综上分析,三峡水库的漫衰减系数主要受颗粒物 的吸收作用以及水体的总散射作用影响,在所选的四 个特征波段里它们贡献率的均值分别为 $45.48 \%$ 和 $38.21 \%$. 而水体的总散射作用同样受到水体中颗粒物 浓度大小的影响, 所以颗粒物浓度与三峡水库水体的 $K_{d}$ 的大小存在相关性, 且应为漫衰减系数变化的最主 要的影响因子. 对 $400-700 \mathrm{~nm}$ 的 $K_{d}$ 与采样点位的颗粒 物以及非色素颗粒物的浓度进行了相关性分析 (图 4), 可以看出在 $400-700 \mathrm{~nm}$ 波段, $K_{d}$ 与颗粒物和非色素颗 粒物的浓度具有很好的相关性, 其中 $K_{d}(400-700 \mathrm{~nm})$ 与颗粒物的相关性的平均值达到 $90.31 \%$, 而与非色素 颗粒物则达到了 $90.52 \%$, 进一步说明三峡水库水体漫 衰减系数主要受颗粒物特别是非色素颗粒物的影响. 
光谱响应函数对实测 $R_{r s}$ 的波段进行等效处理 ${ }^{[27]}, \mathrm{HJ} 1$ 为模拟的环境卫星多光谱数据第一波段, $\mathrm{HJ} 2 、 \mathrm{HJ} 3$ 和 $\mathrm{HJ} 4$ 分别为第二、三、四波段,进而建立三峡水库的 $K_{d}(490)$ 反演模型.

首先, 对模拟的环境卫星多光谱数据的遥感反射率与 $K_{d}(490)$ 以及 $\ln \left[K_{d}(490)\right]$ 进行相关性分析 (表 $2)$. 然后选取与 $K_{d}(490)$ 具有较好相关性的波段 $\ln (\mathrm{HJ} 3)$ 作为自变量, 建立 $K_{d}(490)$ 的反演模型如式 (9) 所示:

表 2 遥感反射率与 $K_{d}(490)$ 以及 $\ln \left[K_{d}(490)\right]$ 的相关性

Tab. 2 Correlation of remote sensing reflectance, $K_{d}(490)$ and $\ln \left[K_{d}(490)\right]$

\begin{tabular}{ccccc}
\hline$K_{d}(490)$ 相关系数 $(\%)$ & $\mathrm{HJ} 1$ & $\mathrm{HJ} 2$ & $\mathrm{HJ} 3$ & $\mathrm{HJ} 4$ \\
& 0.876 & 0.868 & 0.903 & 0.849 \\
\hline \multirow{2}{*}{$\ln \left[K_{d}(490)\right]$ 相关系数 $(\%)$} & $\ln (\mathrm{HJ} 1)$ & $\ln (\mathrm{HJ} 2)$ & $\ln (\mathrm{HJ} 3)$ & $\ln (\mathrm{HJ} 4)$ \\
& 0.940 & 0.939 & 0.959 & 0.909 \\
\hline
\end{tabular}

$$
\ln \left[K_{d}(490)\right]=0.819 \ln (\mathrm{HJ} 3)+4.186\left(R^{2}=0.920, F=137.087, P<0.001\right)
$$

式(9) 可进一步化为:

$$
K_{d}(490)=\mathrm{e}^{0.819 \ln (\mathrm{HJ3})+4.186}
$$

在之前对遥感反射率反演 $K_{d}$ 的相关研究中,有学者认为采用多波段线性回归的方法可以得到较好的反 演效果 ${ }^{[8-9,28-29]}$. 所以在这里选取了不同的波段组合作为自变量, 对 $K_{d}(490)$ 进行多元线性回归,但结果证明 对于 HJ-1 CCD 数据而言, 采用多波段进行反演的结果精度并不优于单波段法. 究其原因, 由于多光谱影像光 谱分辨率较低,波段宽度较大 (例如 $\mathrm{HJ} 3$ 为 $630-690 \mathrm{~nm}$ ), 所以其所含有的光谱信息也不如高光谱影像的单 一和准确,所以在采用多个多光谱的波段进行反演时,其参与反演的干扰因素加大,有用光谱信息的比重反 而下降,从而导致了模型反演精度下降.

\section{3 .2 漫衰减系数的遥感影像反演 采用上文建} 立的模型 (式 10 ) 结合环境一号卫星 $\mathrm{CCD}$ 数据反演 2009 年 7 月 21 日的三峡水库的 $K_{d}(490)$ 值 (图 $5)$. 水库相对于内陆湖泊最重要的区别是具有明显 的纵向梯度,即沿着人库水流的方向, 水库可以分 为 3 个不同的区域, 即河流区、过渡区和湖泊区,每 个区都拥有独特且动态的物理、化学和生物特 点 ${ }^{[30]}$. 三峡水库的湖泊区 $K_{d}(490)$ 主要为 $6-7 \mathrm{~m}^{-1}$ (图 5), 占研究区域面积的 $83.60 \%$, 这是由于水体 中颗粒物含量过高所致,而造成水体中颗粒物含量 过高的原因主要是由于水库上游水体夹带大量泥 沙等进人库区并在水库蓄积, 降低了水体对各种水 质参数的扩散输送能力和生化降解速度, 导致各水 体中颗粒物浓度升高. 研究区中 $K_{d}(490)$ 低于 $6 \mathrm{~m}^{-1}$

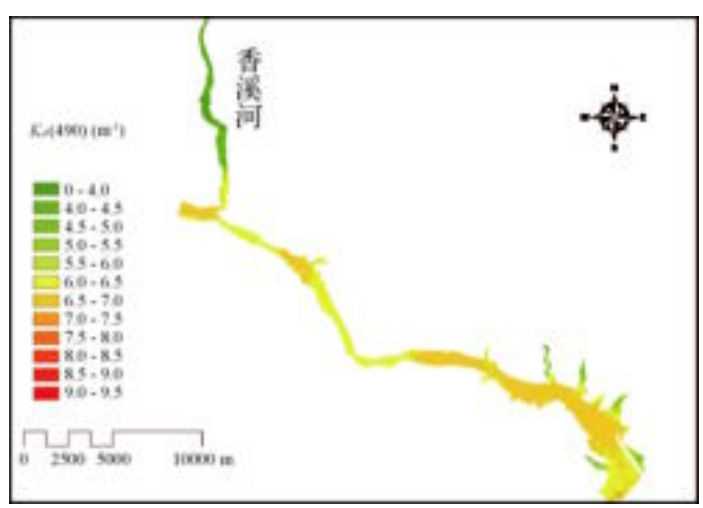

图 52009 年 7 月 21 日 $K_{d}(490)$ 空间分布

Fig. 5 Spatial distribution of $K_{d}(490)$ on July 21 , 2009 的占总面积的 $16.16 \%$, 主要集中在香溪河段,而香溪河段水体的 $K_{d}(490)$ 呈现由河口向支流方向逐渐减小 的趋势, 靠近河口的水体受水库湖泊区高浓度颗粒物的影响,其 $K_{d}(490)$ 与水库湖泊区基本相同, 随河口向 支流方向,香溪河水体受到水库湖泊区的干扰减弱,颗粒物的浓度下降,进而 $K_{d}(490)$ 也随之下降.

2.3.3 漫衰减系数遥感影像反演误差分析 首先, 采用地面实测的高光谱数据模拟星上多光谱数据, 代人 上文建立的漫衰减系数反演模型 (式 10 ), 模拟出的 $K_{d}(490)$ 与实测的 $K_{d}(490)$ 相比具有很好的精度 (图 $6)$, 平均相对误差为 $17.89 \%$. 然后采用星上数据对该模型精度进行检验, 对比实测的 $K_{d}(490)$ 之后发现, 其 获得的精度要比地面模拟星上数据反演的结果略差, 平均相对误差 $28.38 \%$.

分析认为主要原因是:首先, 导致星上数据反演地表水体组分存在误差的一个重要原因就是大气校正 


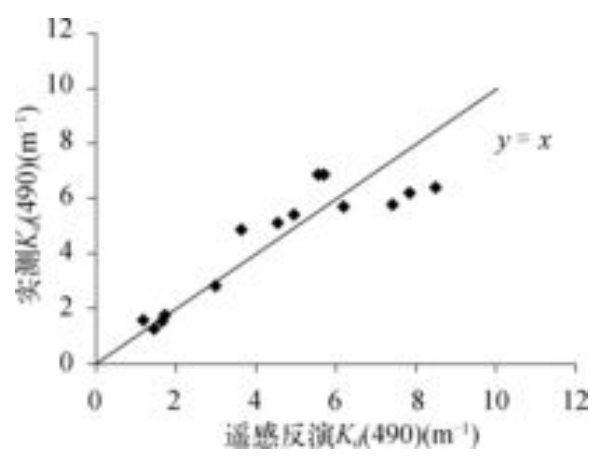

图 6 遥感反演 $K_{d}(490)$ 与实测值对比

Fig. 6 Comparison between the simulated and measured value of $K_{d}(490)$

问题, 从遥感传感器接收到的总辐射量中来自水体的信号 (离水辐射率)很少, $90 \%$ 以上来自于大气瑞利散射、气溶胶 散射以及太阳反射, 因此, 准确获取水色要素遥感信息的前 提是进行精确的大气校正,将水体信息同大气信息分离,是 水色遥感得以应用的关键 ${ }^{[31]}$. 本次研究中采用的 $6 \mathrm{~S}$ 大气校 正模型中部分输人参数由于无法获得, 所以采用了经验值以 及 $6 \mathrm{~S}$ 模型自带的参数, 这就造成大气校正的精度下降, 进而 影响到 $K_{d}(490)$ 反演的结果; 其次, 由于研究中所使用的影 像和实测数据不完全同步, 而水体具有流动性和不稳定性, 所以导致野外实验采集的数据与影像反演的结果存在着相 对误差; 最后, 由于野外实测数据为一个采样点的数据, 而环 境一号卫星的 CCD 数据的空间分辨率为 $30 \mathrm{~m}$, 所以影像上 获取的反演结果为 $900 \mathrm{~m}^{2}$ 范围内 $K_{d}(490)$ 的值, 这也就造成 了实测数据与影像反演数据之间的差异.

\section{3 结论}

(1) 三峡水库水体 $K_{d}$ 在 $400-700 \mathrm{~nm}$ 内的变化趋势和内陆湖泊大体相同, 在 $613 \mathrm{~nm}$ 之前大部分点位呈 指数衰减, 在此之后, 由于不同点位水体组分的构成以及各组分所占的比例不同, 除部分点位因有色颗粒物 含量较高导致 $675 \mathrm{~nm}$ 出现衰减峰值外,其余的点位没有明显的变化.

(2) 三峡水库水体 $K_{d}$ 的影响因子主要有颗粒物、CDOM、纯水的吸收系数以及总散射系数,而其中占主 导地位的是颗粒物的吸收作用以及水体的总散射作用,在所选的四个特征波段 (440、550、613 和 $675 \mathrm{~nm})$ 处 它们贡献率的均值分别为 $45.48 \%$ 和 $38.21 \%$, 而 $K_{d}$ 在 $400-700 \mathrm{~nm}$ 与非色颗粒物物浓度具有很好的幕函数 关系,决定系数到达 0.8561 .

(3) 采用 HJ3 波段进行建模反演, 之后采用地面实测数据和星上数据对模型的精度进行了验证, 平均 相对误差分别为 $17.89 \%$ 和 $28.38 \%$, 在对比了多波段组合模型后表明利用多光谱影像数据反演 $K_{d}(490)$ 时,单波段反演效果要优于多波段组合.

(4) 三峡水库 $K_{d}(490)$ 主要集中在 $6-7 \mathrm{~m}^{-1}$, 占到研究区域面积的 $83.60 \%$, 说明水库水体中的颗粒物 含量很高, 而研究区内人库支流的 $K_{d}(490)$ 较水库的湖泊区要低, 表明其输人水库湖泊区的颗粒物量较少, 导致水库水体中颗粒物含量较高的原因是上游水体中携带了大量泥沙.

致谢: 感谢参加三峡水库实验的所有工作人员在数据获取过程中所作的贡献, 感谢孙德勇博士、乐成峰博士 在论文写作及修改中给予的帮助以及指导意见.

\section{4 参考文献}

[ 1 ] Morel A. Optical properties of pure water and pure sea water, Chapter 1 in Optical Aspects of Oceanography. New York: Academic Press, $1974: 1-24$.

[2] 乐成峰, 李云梅, 查 勇等. 太湖水体漫射衰减系数的光学特性及其遥感反演模型. 应用生态学报, 2009,20(2): 337-343.

[ 3 ] 张运林,秦伯强,陈伟民等. 太湖梅梁湾沿岸带水体生物学与光学特性. 生态学报,2005,25(3):454-460.

[ 4 ] 黄昌春, 李云梅, 乐成峰等. 太湖梅梁湾漫衰减系数季节性差异及其主导因素. 生态学报,2009,29(6) :3295-3306.

[ 5 ] Kirk JTO. The vertical attenuation of irradiance as a function of the optical properties of the water. Limnol Oceanogr, $2003, \mathbf{4 8}(1): 9-17$.

[ 6 ] Gordon HR, McCluney WR. Estimation of depth of sunlight penetration in sea for remote-sensing. Applied Optics, 1975, 14: 413-416.

[ 7 ] Zheng XB, Dickey T, Chang G. Variability of the down welling diffuse attenuation coefficient with consideration of inelastic scattering. Applied Optics, 2002, 41: 6477-6488. 
[ 8 ] Austin RW, Petzold T. The determination of the diffuse attenuation coefficient of sea water using the coastal zone color scanner. In: Gower JFR ed. Oceanography from Space. New York: Plenum Press, 1981 : 239-256.

[ 9 ] Mueller JL. SeaWiFS algorithm for the diffuse attenuation coefficient, $K(490)$, using water-leaving radiances at 490 and $555 \mathrm{~nm}$, Chapter 3 of SeaWiFS Postlaunch Calibration and Validation Analyses, Part 3. NASA Technical Memorandum, $2000,11: 24-27$.

[10］崔廷伟,张 杰,马 毅等. 渤海近岸水体漫衰减系数 $K_{d}(490)$ 遥感反演模型. 遥感学报, 2009,13(3):417-422.

[11] 王 桥, 吴传庆, 厉 青. 环境一号及其在环境监测中的应用. 遥感学报,2010,14(1):113-121.

[12] 李玉荣,闵要武,邹红梅. 三峡工程蓄水水文特性变化浅析. 水文,2009,29(4):37-39.

[13] 许秋瑾,郑丙辉,朱延忠等. 三峡水库支流富营养状态评价方法. 中国环境科学,2010,30(4):453-457.

[14] Mobley CD. Estimation of the remote-sensing reflectance from above-surface measurements. Applied Optics,1999,38(36) : $7442-7455$.

[15] 唐军武, 田国良, 汪小勇等. 水体光谱测量与分析 I : 水面以上测量法. 遥感学报,2004,8(1):37-44.

[16] Huang EH, Pan DL, Li SJ et al. Comparing methods for identifying the outliers in the in-water profile spectral data. Journal of Marine Sciences, 2006, 24(1) : 91-96.

[17] Zaneveld JRV, Kitchen JC, Moore CC et al. Scattering error correction of reflecting-tube absorption meters. Proceedings of SPIE, 1994, 2258 : 44-55.

[18］孙德勇,李云梅, 王 桥等. 太湖水体散射特性及其空间分异. 湖泊科学,2008,20(3):389-395.

[19] Boss E, Pegau S. The relationship of light scattering at an angle in the backward direction to the backscattering coefficient. Applied Optics, 2001, 40 (30): 5503-5507.

[20] Giulietta SF, James LM. Ocean optics protocols for satellite ocean color sensor validation. NASA. TM-2003211621,2003 .

[21] Huovinen PS, Penttol H, Soimasuo MR. Spectral attenuation of solar ultraviolet radiation in humic lake in Central Finland. Chemosphere,2003,51(3) : 205-214.

[22] 张运林,秦伯强. 太湖水体光学衰减系数的分布及其变化特征. 水科学进展,2003,4(14):447-453.

[23] 中国长江三峡集团公司. 水情实况. http://www. ctgpc. com. cn/sx/sqsk. php.

[24] 中国资源卫星应用中心. 环境减灾星座 A/B 星各载荷在轨绝对辐射定标系数,2009. (2009 - 11 - 30, http://www. cresda. com/n16/n1115/n1522/n2103/n9592. files/n9595. pdf).

[25] 黄昌春,李云梅, 孙德勇等.太湖水体漫衰减系数特征及其对水生态环境影响分析. 环境科学, $2009, \mathbf{3 0}$ ( 2 ) : $348-355$.

[26] Pope RM, Fry ES. Absorption spectrum $(380-700 \mathrm{~nm})$ of pure water. II. Integrating cavity measurements. Applied Optics, $1997, \mathbf{3 6}(33): 8710-8723$.

[27] 孙 凌, 王晓梅, 郭茂华等. MODIS 水色产品在黄海海域的真实性检验. 湖泊科学,2009,21(2):298-306.

[28] 王晓梅, 唐军武, 丁 静等. 黄海、东海二类水体漫衰减系数与透明度反演模式研究. 海洋学报, 2005,27 ( 5): $38-45$.

[29] Lee ZP, Du KP, Arnone R. A model for the diffuse attenuation coefficient of downwelling irradiance. Journal of Geophysical Research, 2005, 110( C02016) (doi:10. 1029/2004JC002275).

[30] 徐耀阳,王 岗,韩新芹等. 三峡水库香溪河库湾春季水华期间悬浮物动态. 应用生态学报,2009,20 (4):963-969.

[31] 王海君. 太湖水色遥感大气校正方法研究 [学位论文]. 南京:南京师范大学,2007. 